\title{
Direct and Indirect Costs Associated with Coronary Artery (Heart) Disease in Tabriz, Iran
}

This article was published in the following Dove Press journal:

Risk Management and Healthcare Policy

\author{
Shahla Darba' \\ Naser Safaei ${ }^{2}$ \\ Alireza Mahboub-Ahari (iD ${ }^{3}$ \\ Shirin Nosratnejad ${ }^{3}$ \\ Gisoo Alizadeh (iD) \\ Hosein Ameri (iD ${ }^{5}$ \\ Mahmood Yousefi iD $^{3}$ \\ 'Department of Health Economics, \\ School of Management and Medical \\ Informatics, Tabriz University of Medical \\ Sciences, Tabriz, Iran; ${ }^{2}$ Madani Heart \\ Center, Tabriz University of Medical \\ Sciences, Tabriz, Iran; ${ }^{3}$ Department of \\ Health Economics, Iranian Center of \\ Excellence in Health Services \\ Management, School of Management and \\ Medical Informatics, Tabriz University of \\ Medical Sciences, Tabriz, Iran; \\ ${ }^{4}$ Department of Health Policy and \\ Management, Iranian Center of \\ Excellence in Health Management, School \\ of Management and Medical Informatics, \\ Tabriz University of Medical Sciences, \\ Tabriz, Iran; ${ }^{5}$ Health Policy and \\ Management Research, Department of \\ Health Care Management, School of \\ Public Health, Shahid Sadoughi University \\ of Medical Science, Yazd, Iran
}

Purpose: Cardiovascular diseases (CVDs) are the major causes of mortalities worldwide. This study was conducted to evaluate the direct and indirect costs of coronary artery disease (CAD) in Iran.

Patients and Methods: This is a prevalence-based cost-of-illness (COI) study that estimates the direct and indirect costs of CAD. The study conducted over a six-month period from April to September in 2017. Patients were recruited from Madani hospital in Tabriz, Iran. A total of 379 patients were investigated from societal perspective. Direct costs were estimated using the bottom-up costing approach and indirect costs were estimated using the Human Capital (HC) approach. A generalized linear model of regression was used to explore the relation between total cost and socio-demographic variables. The total annual mean cost was compared to Gross Domestic Product (GDP) per capita which was reported in the form of Purchasing Power Parity (PPP) index. To deal with uncertainty, one-way sensitivity analysis was performed.

Results: Total costs per patient in one year were estimated to be IRR 63452290.17 (\$PPP 7736.19) at a 95\% confidence interval (58191511.73-68713068.60), the biggest part of which is related to direct medical costs with IRR 33884019.53 per year (\$PPP 4131.18) (54\%). Direct non-medical costs were estimated IRR 1655936.68 (\$PPP 201.89) per patient (2\%) and indirect costs were estimated IRR 27912333.97 per patient (\$PPP 3403.11) (44\%), which $62 \%$ of indirect costs is related to patients' work absenteeism.

Conclusion: This study estimates the direct (56\%) and indirect (44\%) costs associated with CAD. The study explores the essential drivers of the costs and provides the magnitude of the burden in terms of the share of GDP. The outcomes can be used in priority setting, in particular for cost benefit analysis, and adopting new policies regarding insurance coverage and equity issues.

Keywords: coronary heart disease (CHD), direct cost, indirect cost, cost-disease analysis

\section{Introduction}

Cardiovascular disease (CVD), specifically coronary artery (heart) disease (CAD), has been introduced among the most common causes of death at all ages in both genders. ${ }^{1}$ CVDs as the major Non-communicable Diseases (NCDs), are responsible for 17.9 million deaths, accounting for $44 \%$ of all NCD deaths and $31 \%$ of all global deaths. ${ }^{2}$ CAD constitutes over $40 \%$ of the deaths attributable to CVD. ${ }^{3}$

The devastating effects of the disease are not limited to the physical and psychological effects on the person, but it affects the family and society economically. The scarcity of resources and increased social expectations has made it necessary to prioritize resources to meet health care needs. Any planning to
Correspondence: Mahmood Yousef Department of Health Economics, Iranian Center of Excellence in Health Services Management, School of Management and Medical Informatics, Tabriz University of Medical Sciences, Tabriz, Iran

Tel +989121755785

Fax $+984 I-33251362$

Email mahmoodyousefi59@gmail.com 
prioritize resource allocation for disease control requires gaining information and knowledge on the level and dimensions of the effects of the diseases. One of the main issues that is concerned with efficient prioritizing and allocation of resources is to quantify the effects and dimensions of the diseases ${ }^{4,5}$ and then to express them in a monetary term. ${ }^{6}$

In addition, due to specific health care characteristics such as unpredictability of service utilization and low elasticity of services, patients may experience catastrophic costs in using services. $^{7}$ One of the functions of health systems is to protect individuals from the catastrophic costs. Any planning for financial protection of individuals requires evidence regarding the financial burden of the disease and the distribution of its components. Hence, it is not surprising that concern on people's health expenditures have nowadays drawn the attention of many policymakers and academics worldwide. ${ }^{8}$ Depending on the aim of the costing analysis there are a wide range of studies that have used various methodology to explore the financial burden of different diseases in health system. ${ }^{9-11}$ Cost-of-illness (COI) study is one of the most common approaches used to evaluate the impact of an illness on the population. It presents an explanation of the utilized resources and the lost resources with regard to an illness. ${ }^{12}$ This method estimates costs according to the size and scope of the effect, so that costs are socially divided into direct and indirect costs. Intangible costs are usually not considered due to methodological considerations. Direct costs include direct therapeutic and non-therapeutic costs (e.g., commuting and accommodation costs, etc.). Indirect costs are calculated by estimating lost productivity in other sectors of the economy. This financial burden will vary depending on the socio-economic structure of the countries, technological changes, health sector structural changes, and illness patterns. Thus, any society with its own structure and for different time periods needs to understand the financial burden of different illnesses. ${ }^{6}$ The ultimate goal of a COI study is to provide the objective evidence needed for policymaking, designing, and managing of health plans. Comparison of coronary heart illness costs across countries with different health systems can help to better understand the economic consequences of different health policies and plans. Addressing these issues, this study was conducted with the aim of examining the direct and indirect costs of CAD patients.

\section{Patients and Methods}

This study is a prevalence-based COI study conducted using bottom-up approach in April to September 2017. A consecutive sample of 400 patients with coronary heart disease (CHD; ICD-10 category I20-I25) who were hospitalized in Tabriz`s Madani hospital were studied. Of which 21 patients were excluded from the study in the second and third follow-up stages due to a lack of willingness to cooperate, patient death and incorrect patient information. Finally, 379 samples were included. The hospital is one of the educational, and research hospitals for heart diseases in Iran. Patients were followed for six months with three twomonth periods. The study was conducted from societal perspective and included both direct and indirect costs. In societal perspective, a full analysis of all the opportunity costs attributed to an illness is examined. ${ }^{13,14}$ In the prevalencebased approach, costs are measured for a given period, usually one year, of time. In fact, the time of onset of the illness is not important and the patients might be the old or newly diagnosed patients. ${ }^{15}$ In this method instead of following a patient with a given illness for entire disease period to explore all sates experienced by the patient, the patients from different stages (old or newly diagnosed) are included and followed for a shorter period of time. The total costs, direct costs, and indirect costs, were estimated as outcome measures and intangible costs were not included in this study. In the bottom-up approach the costs are estimated firstly by calculating the average cost of an illness then it is multiplied by the prevalence of the illness. The bottom-up approach applies three steps of identifying, measuring, and valuation of resources forgone due to the illness. The average total cost in bottom-up approach often calculated by adding together the various components of the allocated costs. To extract the identified items a checklist was developed in four sections as follows: 1) socio-demographic information; 2) direct medical costs; 3) direct non-medical costs; and 4) indirect costs. The checklist included 31 close-ended and open-ended questions. Questions on patients' demographic information, general health status of patients, insurance coverage, job status, days of absenteeism, direct medical costs including costs of medical visit, emergency services, drug, hospitalization, rehabilitation and medical devices needed for coronary artery disease (CAD), direct non-medical costs, including patient and their family commuting to diagnostic and treatment centers, staying in another city, receiving complementary treatments such as herbal remedies and special diets, taking care of the patient at home, and auxiliary equipment and supplies. The total annual mean was then compared to gross domestic product (GDP) per capita which was reported in the form of purchasing power parity (PPP) index. The results were calculated as the mean cost per patient over a one-year period. 


\section{Direct Medical Costs}

The direct medical cost covers the value of all services, including drug, visit, test, echocardiography, ECG, cardiac stress test, angiography, surgery, other drugs, imaging, ambulance and consultation.

The direct medical cost data was derived from patients' medical records and interviews with patients or their caregivers to estimate the medical services or drugs that were purchased outside of the hospital. Cost items were identified through consulting with specialists, reviewing literature and clinical guidelines. The direct medical cost calculation was reported in the form of PPP (2016).

\section{Direct Non-Medical Costs}

The direct non-medical costs represent the value of nonhealthcare resources like transportation costs to health care providers, household expenditures, relocating, and property losses due to an illness. ${ }^{16}$ In order to calculate direct non-medical costs, the required information was collected using two methods of face-to-face interview and telephone interview. Demographic and first round of cost information was collected during face-to-face interview at the time of discharge and the second and third round of data collection was performed by telephone interview. At the time of discharge all patients had been informed about the next calls and what information was expected to be gathered from them. The mean costs of food, accommodation and travel per patient were calculated in the study period to estimate direct non-medical costs.

\section{Indirect Costs}

Indirect cost refers to the production lost due to the illness. ${ }^{17-19}$ To estimate the indirect costs, the human capital (HC) approach was used. The lost income of people was considered as a productivity index and GDP per capita for the active population in the study year was considered as an index for lost income. ${ }^{16,20}$ Indirect costs were estimated by calculating the mean cost of premature death and absenteeism of patients and their caregivers per year. To estimate patients' lost production, the number of hospitalization days and the number of days of resting at home due to illness was multiplied by daily GDP per capita for active population (GDP 2016). For outpatient visits the number of days of patient referral for outpatient visit, considered half days of hospitalization, was multiplied by daily GDP per capita for active population and the calculation was adjusted to PPP unit. In order to estimate the cost of premature death, mortality rates of coronary heart disease in the country were obtained using the data from NCD Center at Iran's Ministry of Health. ${ }^{21}$ The obtained mortality figures then were applied in the study sample to obtain the annual mortality rates for the 5 -year age groups within the whole sample. Considering the mean retirement age of 65 years for patients, this value was deducted from the mean of any age group and multiplied by the mortality numbers to obtain total lost years in each group. Finally, it was multiplied in annual GDP per capita for active population. According to the previous literature the formulas used to calculate the cost of patient production lost, ${ }^{16,20,22,23}$ customized as follows:

(Number of patient hospitalization day $\times$ GDP per capita for active population (daily) (2016)) + (number of days of resting at home $\times$ GDP per capita of active population (daily) (2016)) + (number of outpatient visit $\times 0.5 \times$ GDP per capita for active population (daily) (2016)) + (number of premature death years $\times$ annual GDP per capita of active population (2016)) $=$ total cost of patients' production lost.

Cost of production lost per patient $=$ total cost of production lost/379 patients)

To calculate the cost of the patient caregiver's production lost, the number of days of absenteeism was multiplied by the daily GDP per capita of the active population. Finally, the mean cost of patient lost production was adjusted to the international currency.

Formula used to calculate the patient's caregiver lost production cost:

Cost of production lost per patient's caregiver $=$ total cost of patients' caregivers production lost $/ 379$ patients.

A regression analysis was conducted to understand the relation between the total cost and socio-demographic variables. Since the cost variable was distributed non-normally then the Generalized Linear Method with Gamma distribution and identity link function was applied, ${ }^{24,25}$ the regression analysis was run using the STATA 14.

And finally, to generalize the results of this study to the whole country the total median cost per patient was multiplied by the total numbers of the patients throughout the country. Due to high skewed data, at this stage we used the median of total cost, instead of the mean, to extrapolate the results for whole country. The total numbers of the patients with concerned ICD-10 codes were obtained based on the prevalence rate from NCD Center at Iran's Ministry of Health. ${ }^{21}$ 


\section{Dealing with Uncertainty}

One-way sensitivity analysis was performed to deal with uncertainty in the parameters influencing the cost outcomes. All parameters were changed at $20 \%$ and $50 \%$ intervals. The intervals were set based on the experts opinions. In direct medical costs, the parameters of drug, angiography, surgery and hospitalization were changed. For direct non-medical costs the distance parameter was changed, and for indirect costs, per capita GDP and retirement age (from age 65 to age 60) parameters were changed. Only the most influential parameters were selected for sensitivity analysis.

\section{Results}

Costs of 379 patients were estimated in the present study. Out of all samples studied, $72.3 \%$ were male and $27.7 \%$ were female. The results of this study revealed that $98.7 \%$ of patients were covered by insurance and $1.3 \%$ had no insurance coverage. A small proportion of patients were covered by supplemental insurance (14.4\%). The mean age of the patients was 61 (SD 9.41) years, minimum and maximum age range was 31 and 90 years, respectively. The hospitalization length was ranged from 2 to 60 days (Mean 10.34, SD 9.35). Table 1 (demographic characteristics of the patients)

\section{Costs}

In this study, 21 types of costs related to CAD were identified. These costs generally include direct medical costs, direct nonmedical costs, and indirect costs. The total cost of CAD was IRR 63452290.17 (\$PPP 7736.19) per patient for one year. Most of the costs belonged to direct medical costs IRR 33884019.53 (\$PPP 4181.18) (54\%), direct non-medical costs was IRR 1655936.68 (\$PPP 201.89) (2\%) and indirect costs was IRR 27912333.97 (\$PPP 3403.11) (44\%) per patient for one year. Figure 1 represents the direct medical, direct nonmedical and indirect costs in patients with CAD.

The largest part of total costs belonged to direct medical costs. Based on Table 2, the greatest costs in patients with CAD were related to surgery with an annual mean of IRR 15876792.71 (\$PPP 1935.72) (0.24\%) and the lowest costs related to ambulance transportation with an annual mean of IRR 101752.86 per year (\$PPP 12.40) (0.001\%). In total, surgery and angiography costs account for more than $50 \%$ of direct medical costs (see Figure 2).

Table 3 illustrates the direct non-medical costs. As the majority of clients were living in rural or suburban areas,
Table I Demographic Characteristics of the Patients ( $N=379)$

\begin{tabular}{|l|l|l|l|}
\hline Demographic Variables & N & Percentage \\
\hline Sex & Male & 274 & 72.3 \\
& Female & 105 & 22.7 \\
\hline Age & $31-40$ & 7 & 1.85 \\
& $41-50$ & 39 & 10.30 \\
& $51-60$ & 88 & 23.2 \\
& $61-70$ & 170 & 44.85 \\
& $71-80$ & 68 & 17.95 \\
\hline Medical & $81-90$ & 7 & 1.85 \\
\hline insurance & Yes & 374 & 98.7 \\
\hline $\begin{array}{l}\text { Type of } \\
\text { insurance }\end{array}$ & No & 5 & 1.3 \\
& Social Security & 105 & 27.5 \\
& Armed Forces & 11 & 2.9 \\
& Health insurance & 250 & 66 \\
\hline Supplemental & Yran's Imam Khomeini & 8 & 2.1 \\
insurance & Relief Committee & & \\
\hline Residential \\
place & No & 87 & 23 \\
\hline Location & Resident & 292 & 77 \\
\hline & Non-resident & 110 & 29 \\
& Urban & 269 & 71 \\
\hline & Rural & 277 & 73.09 \\
& & 102 & 26.91 \\
\hline
\end{tabular}

transportation and travel costs were considered as one of the cost items for most clients. The mean direct nonmedical costs per patient for one year is IRR 1655936.68 (\$PPP 201.89). Travel and food costs with a mean cost of IRR 28222126.74 (\$PPP 351.39) and IRR 118802.22 (\$PPP 14.48) for one year per patient were the highest value among direct non-medical costs, respectively (see Figure 3).

\section{Direct medical cost, Direct non medical cost, Indirect cost}

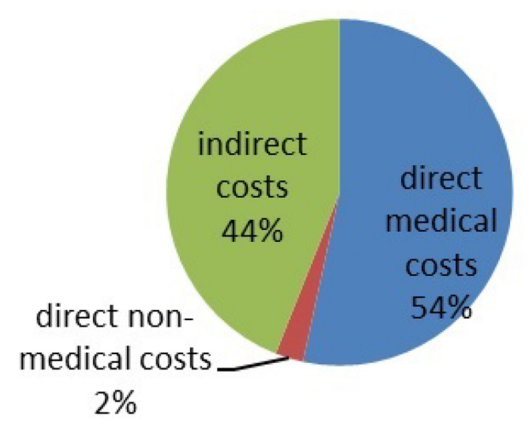

Figure I Direct medical, direct non-medical and indirect costs in coronary artery disease patients (percentage). 
Table 2 The Subcategories of Direct Medical Costs in Patients with Coronary Artery Disease in 2017

\begin{tabular}{|l|l|l|l|l|l|l|}
\hline Costs & Min & Max & Mean (IRR) & Mean (\$PPP) & Standard Deviation (IRR) & The Standard Error (IRR) \\
\hline Echocardiography & 0 & 43756.40 & 1886422.41 & 229.99 & 2257.75 & 115.66 \\
Electrocardiography & 0 & 13254.08 & 571409.01 & 69.66 & 679.32 & 34.80 \\
Other drugs & 0 & 53833.21 & 2314777.52 & 282.22 & 2786.48 & 142.56 \\
Drug & 0 & 275371.86 & 11809815.58 & 1439.87 & 14094.127 & 720.17 \\
Visit & 0 & 47264.08 & 2027004.82 & 247.13 & 123.50 & 2417.05 \\
Test & 0 & 9551.49 & 409633.17 & 49.94 & 491.27 & 25.10 \\
Cardiac stress test & 0 & 9181.90 & 393782.52 & 48.01 & 482.94 & 24.67 \\
Imaging & 0 & 69716.16 & 2989902.71 & 364.53 & 4569.30 & 233.48 \\
Stent & 0 & 90612.04 & 3886059.92 & 473.79 & 4912.45 & 251.01 \\
Angiography & 0 & 292945.62 & 12563497.87 & 1531.76 & 14971.08 & 764.98 \\
Ambulance & 0 & 2472.56 & 106040.49 & 12.92 & 132.81 & 6.78 \\
Consultation & 0 & 2372.59 & 101752.86 & 12.40 & 8.42 & 164.95 \\
Surgery & 0 & 370202.38 & 15876792.71 & 1935.72 & 19187.83 & 980.45 \\
Hospitalization & 0 & 285186.53 & 12230735.69 & 1491.18 & 14582.3 & 745.14 \\
\hline
\end{tabular}

Based on the calculations, the indirect costs of coronary heart disease were IRR 27912333.97 per one year per patient (\$PPP 3403. 11). The costs of premature death were IRR 136367.32 (\$PPP 16.62) per year per patient, and the costs of patient caregiver lost production were IRR 9965136.54 (\$PPP 1214.696) per year per patient. Due to the longer hospitalization, patients incur large costs, and absenteeism costs account for a large part (approximately 87\%) of indirect costs and males accounted for the largest part of indirect costs (see Figure 4 and Table 4) .

\section{Regression Analysis}

Table 5 represents the results of GLM regression analysis. As shown the age and gender were significantly associated with total cost $(\mathrm{P}<0.05)$. The values of $\mathrm{AIC}$ and $\mathrm{BIC}$ were, 32.541 and -1891.421 , respectively.

\section{Sensitivity Analysis}

Figures 5 and 6 show the results of a series of one-way sensitivity analysis to change the case parameters. Horizontal axis shows the percentage of change in total cost for a given level of changes ( $20 \%$ and $50 \%)$ in desired parameters. For example, as a result of a $50 \%$ increase in surgery costs, total costs relative to base changes changed by $23 \%$ and $20 \%$ increase in angiographic costs caused that total costs to change from 63452290.16 to 47144248.74 .

The costs of surgery, angiography and hospitalization showed the highest sensitivity to $20 \%$ and $50 \%$ changes in

\section{Direct medical costs}

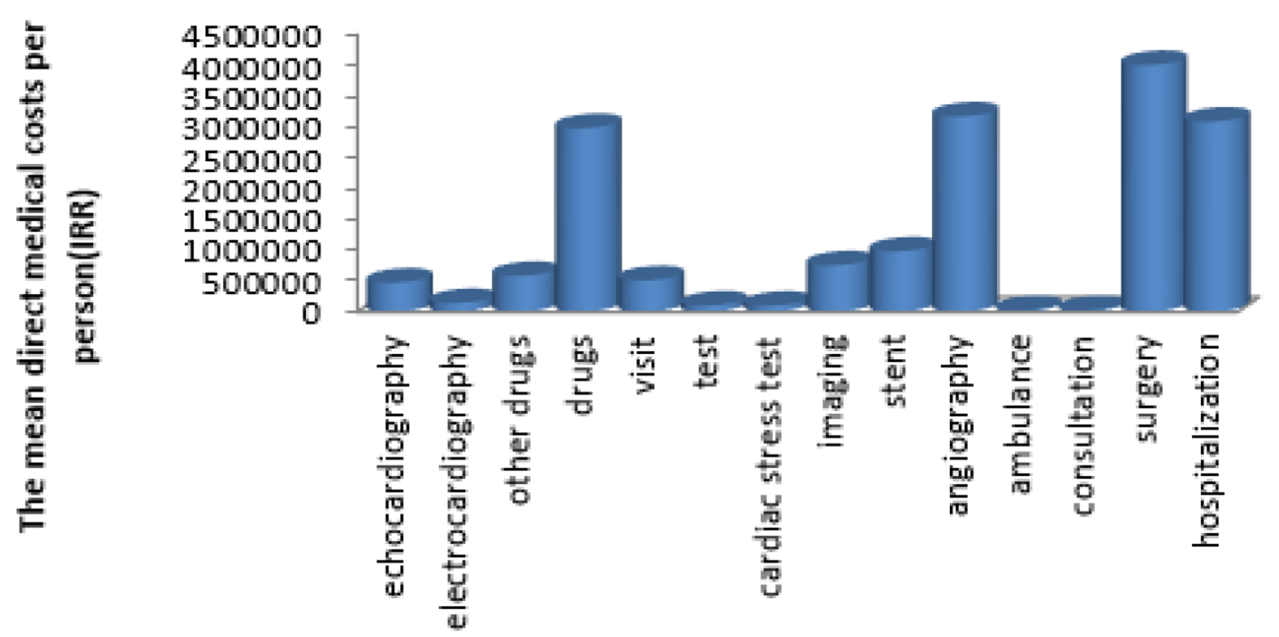

Figure 2 The direct medical costs in coronary artery disease patients (IRR). 
Table 3 Mean Direct Non-Medical Costs in Patients with Coronary Artery Disease

\begin{tabular}{|l|l|l|l|l|l|l|}
\hline Costs & Max & Min & Mean (IRR) & Mean (\$PPP) & Standard Deviation (IRR) & The Standard Error \\
\hline Travel & 0 & 67203.12 & 2882126.74 & 351.39 & 175.31 & 3430.97 \\
Food & 0 & 487.68 & 118802.22 & 14.48 & 56.18 & 2.86 \\
Accommodation & 0 & 2194.58 & 80681.06 & 9.83 & 116.14 & 5.92 \\
\hline
\end{tabular}

total costs, while travel and premature death costs showed the lowest sensitivity to changes.

\section{Discussion}

The rapid increase in CVDs is one of the major health challenges in the present century. ${ }^{26}$ This study evaluated the direct and indirect costs of coronary heart disease, which total costs reported per patient for one year. The largest share of the total costs related to direct medical costs which accounted for $53 \%$ of the costs. This result is in line with the results of other studies conducted in this area, a study assessed the costs of CVD in eight Asian countries reported the share of direct costs out of total costs ranging from $34 \%$ to $52 \%{ }^{27}$ Surgical interventions in this study accounted for most direct medical costs $(25 \%)$. In this study, one of the main reasons for the higher direct costs than indirect costs are

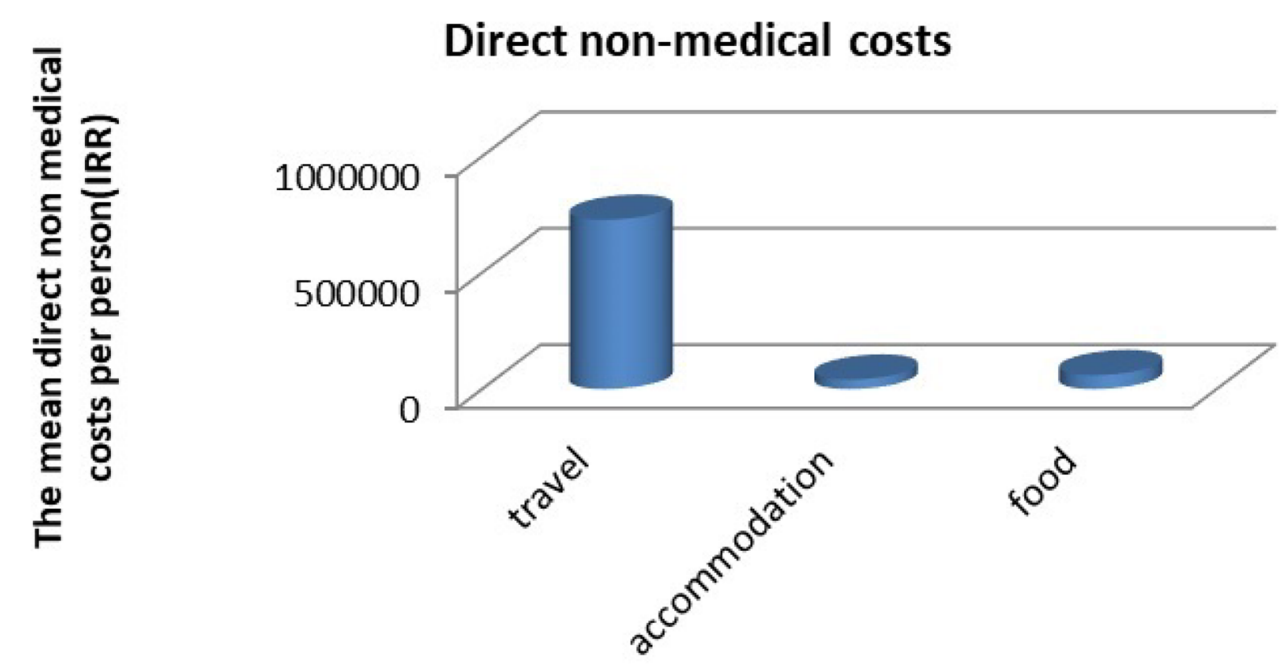

Figure 3 Direct non-medical costs in coronary artery disease patients (IRR).

\section{Indirect costs}

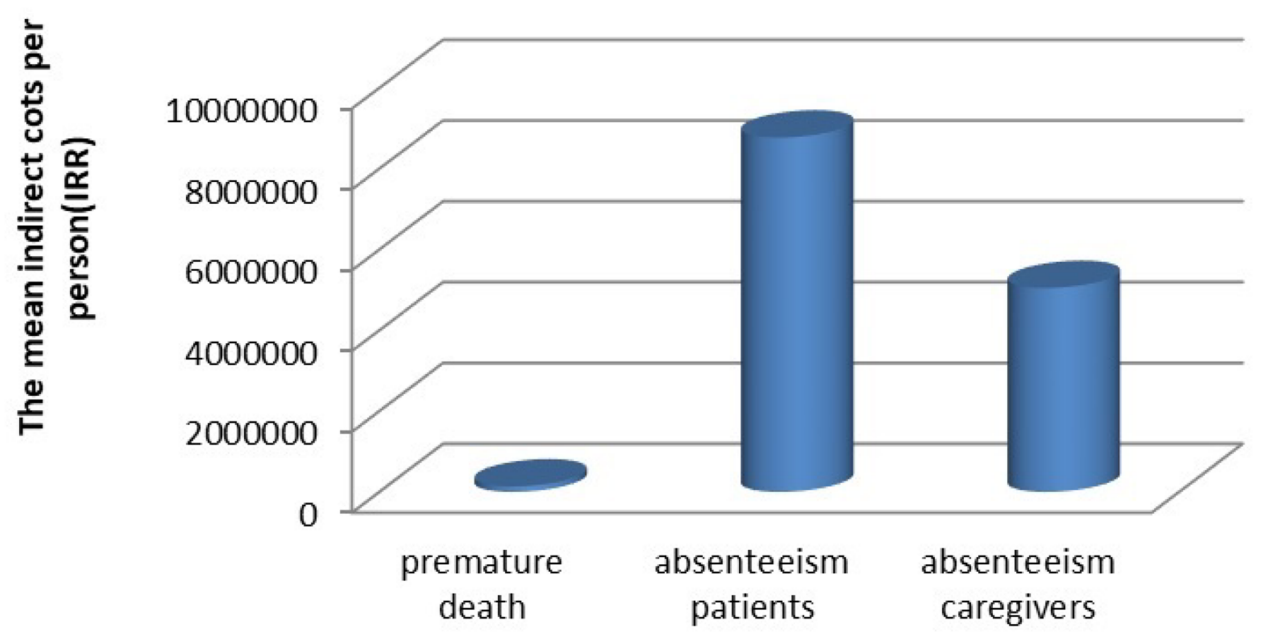

Figure 4 Indirect costs in coronary artery disease patients (\$PPP). 
Table 4 Mean Indirect Costs in Patients with Coronary Artery Disease

\begin{tabular}{|l|l|l|l|l|l|l|}
\hline Costs & Min & Max & Mean (IRR) & Mean (\$PPP) & Standard Deviation (IRR) & The Standard Error (IRR) \\
\hline Absenteeism patients & 0 & 8005.82 & 17314572.16 & 2111.01 & 1400.93 & 71.49 \\
Absenteeism caregivers & 0 & 6625.50 & 1214.96 & 9965136.54 & 806.79 & 41.17 \\
\hline
\end{tabular}

Table 5 The Results of Generalized Linear Model Regression

\begin{tabular}{|l|l|l|l|}
\hline Variables & Coeff. & $\mathbf{Z}$ & P-value \\
\hline Insurance & -7418.9 & -0.03 & 0.981 \\
BMI & -83162.1 & -0.59 & 0.787 \\
Female & -3.812 & -5.03 & 0.019 \\
Age & -2.132 & -5.13 & 0.017 \\
Urban & -2.132 & -1.43 & 0.123 \\
Constant & 838743.5 & 1.16 & 0.247 \\
AIC & 32.54129 & & \\
BIC & -1891.421 & & \\
\hline
\end{tabular}

the high payments to staff in the health sector relative to other sectors in Iran. The higher proportion of the inactive people among the patients is another reason for lower share of the indirect costs. The transportation and travel costs accounted for main $(80 \%)$ direct non-medical costs. It's mainly due to the long distance of the hospital to living place of the clients. Increasing direct and indirect costs due to distance is one of the issues that can be discussed in terms of justice. As distance costs are not part of the cost of insurance coverage, their increase may be one of the factors affecting access and demand for healthcare services for these patients. ${ }^{27}$ This study has also estimated indirect costs as $44 \%$ of total costs which is consistent with other studies conducted in the region. $^{28}$ In estimating the indirect costs the human capital approach in comparison with alternative methods, ${ }^{17}$ overestimates the costs for a given disease. It is because it considers the costs incurred due to premature death until the end of the working age. For present study, more than $60 \%$ of indirect costs related to absenteeism.

One of the important factors in indirect costs (productivity loss) is the retirement age, which different values of indirect costs might be obtained for different retirement age thresholds. Another point is the age at which the disease starts, as the higher the age of start the less the productivity is lost. The advances in technology and the availability of effective interventions in CAD patients increase the cost of treatment and hence the direct costs. In addition, these technologies reduce the mortality at low age and consequently reduce the indirect costs due to premature death. At the same time this may lead to increasing proportion of absenteeism costs. Direct medical costs are costs that usually covered by health insurance schemes but indirect costs are not covered by health insurance schemes. Thus, on the presumption that the insurance schemes are in place, the development of therapeutic technologies will decrease total burden that borne by households. ${ }^{29}$

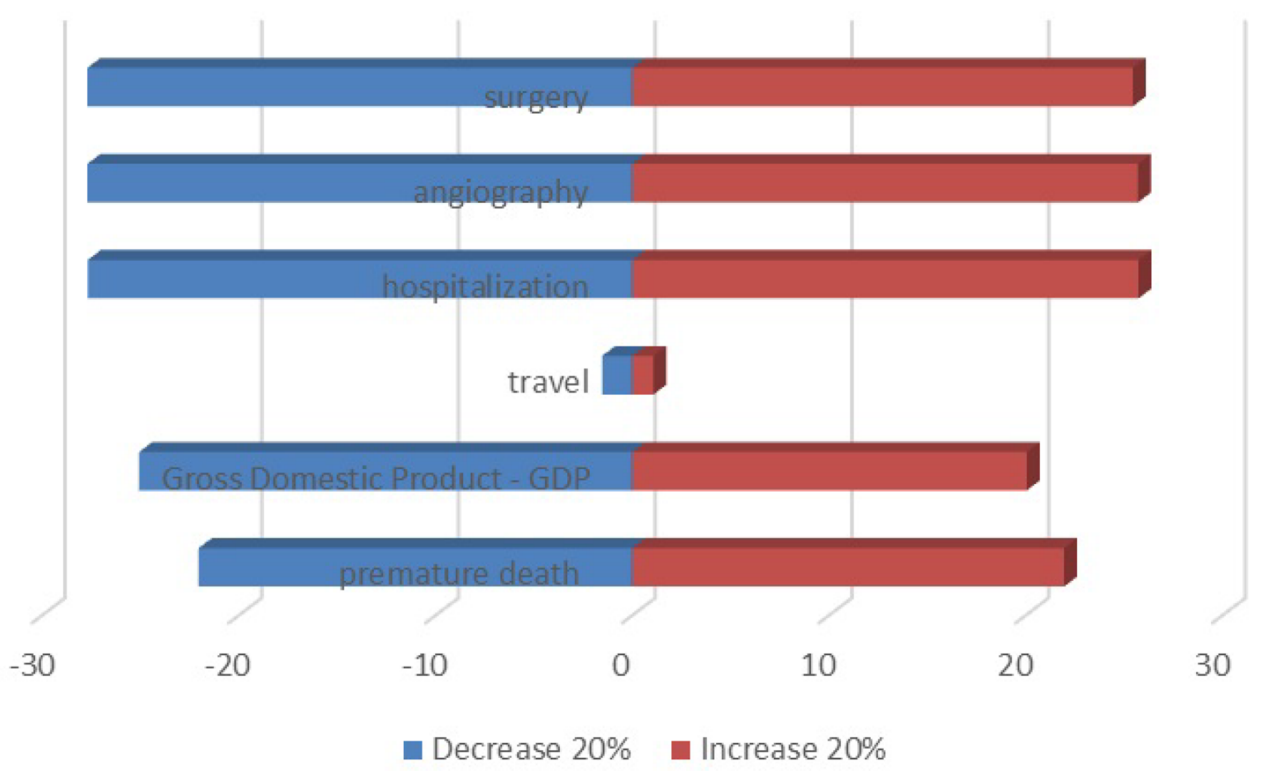

Figure 5 The effect of $20 \%$ change in surgery, angiography, hospitalization, travel, GDP per active person, premature death on total costs. 


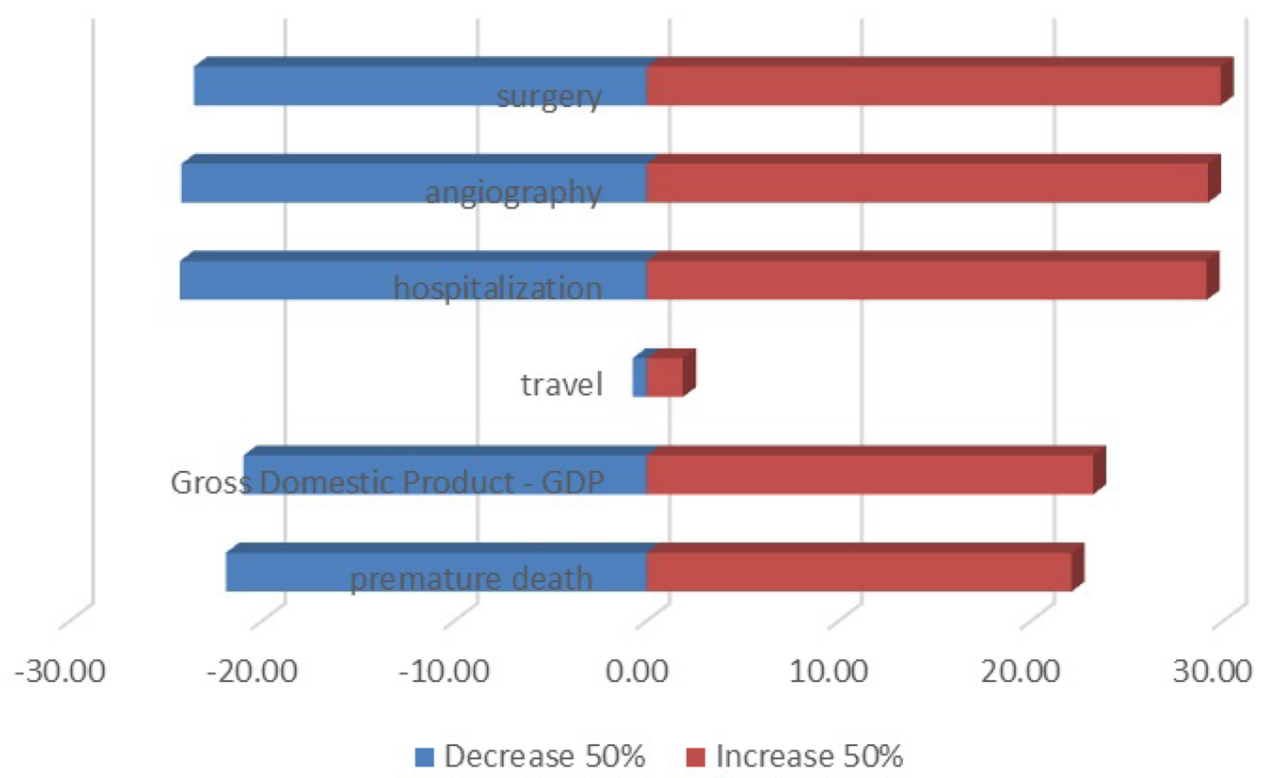

Figure 6 The effect of 50\% change in surgery, angiography, hospitalization, travel, GDP per active person, premature death costs on total costs.

The magnitude of economic burden incurred by coronary heart disease can be better shown by comparing the total cost of the disease in the economy with GDP in that economy. The incidence of total CAD in Iran was 1027 in 100, 000 person-years reported. ${ }^{30}$ According to the results of the present study, the total cost of incidence of coronary heart disease in 2016 was approximately $0.5 \%$ of GDP. A study conducted in Korea estimated the costs of coronary heart disease $0.32 \%$ of the GDP $^{31}$ Other studies have compared the costs of CVD to GDP showed that in Serbia in 2009 the total direct and indirect costs accounted for approximately $1.8 \%$ of $\mathrm{GDP}^{32}$ Total costs of CVD accounted for $3.37 \%$ of the US GDP in $2009 .{ }^{33}$ Moreover, the results of studies in China revealed that the direct medical costs of s (CVDs accounted for 0.62\% of GDP is $2003 .^{34}$ Due to high burden of CAD, it is necessary to reduce costs incurred by patients through strengthening insurance coverage and further intervening of government. The development of preventive interventions focusing on modification of lifestyles will result in saving in costs. The resources saved from this investment can be spent on other plans and other sectors of the economy, leading to an increase in well-being of the community.

The regression analysis showed that age and gender had significant effect on the total cost. This findings was consistent with other studies were conducted on heartrelated disorder. ${ }^{35,36}$ The correlation between total cost and aging was negative, while it is expected to be positive.
The reason can be explained by indirect costs because as age increases the indirect cost of production lost is decreasing. The $\mathrm{HC}$ approach just considers the production value of people by the age of the retirement.

This study estimates coronary artery costs from a social perspective. It provides useful information for health policymakers and decision-makers about the financial burden and composition of patient cost components. Adhering to a systematic methodology including a broader perspective, a bottom-up estimation method, follow-up of patients for a period of six months and frequent contacts with patients every two months, it adds valid and accurate evidence to the scientific literature. In spite of these benefits, it may suffer from some limitations, such as non-randomness of selected samples, conservatism of respondents in stating real costs, and the probability of error in reporting the costs incurred due to recall bias. This shortcoming was partially resolved by using the cases available in the patient's medical record and the interviewing with the patients or their caregivers. In addition, one-way sensitivity analysis was used to explore the potential uncertainties effects. ${ }^{37}$ The $\mathrm{HC}$ approach does not consider intangible costs. Patients for this study were recruited from a public hospital and due to poor quality of health care in the public sector; rich patients usually refer to the private sector for receiving high quality services. ${ }^{38}$ Prices in private sector almost are high in comparison to public sector. Thus, considering this assumption there might be an underestimation in our study. 


\section{Conclusion}

Investigation of the financial burden of the CVDs is crucial due to the fact that CVDs in Iran are ranked first in terms of mortality. CVDs are a group of highcost diseases that can cause high economic burden on society. Additionally, the results revealed that reducing these costs is necessary by strengthening the insurance coverage and further assistance of government, including coverage of drugs prescribed for these patients in public sectors and exempting of poor and low-income people from diagnosis and treatment costs. Reduction of these costs through preventing of these diseases will lead into saving and thus government will be able to use this part of GDP in other sectors to improve the conditions of the country. Cost information provided in this study can be used to conduct cost benefit analysis for CVD prevention programs in terms of cost per averted cases.

\section{Abbreviations}

CVD, Cardiovascular diseases; COI, Cost-of-illness; GDP, Gross Domestic Product; NCDs, Non-communicable Diseases; CHD, Coronary heart disease; PPP, Purchasing Power Parity; CAD, Coronary artery disease; ECG, Electrocardiogram.

\section{Acknowledgments}

We are most grateful and extend our sincere thanks to all people who participated in this study. This paper has been extracted from part of ShD's master thesis, supervised by MY and supported by Tabriz University of Medical Sciences (approval ID: IR.TBZMED.REC.1396.137).

\section{Disclosure}

The authors report no conflicts of interest in this work.

\section{References}

1. Sanchis-Gomar F, Perez-Quilis C, Leischik R, Lucia A. Epidemiology of coronary heart disease and acute coronary syndrome. Ann Transl Med. 2016;4(13):256. doi:10.21037/atm.2016.06.33

2. Benjamin EJ, Muntner P, Alonso A, et al. Heart disease and stroke Statistics-2019 update a report from the American Heart Association. Circulation. 2019.

3. Virani SS, Alonso A, Benjamin EJ, et al. Heart disease and stroke statistics-2020 update: a report from the American Heart Association. Circulation. 2020;E139-E596.

4. Yousefi M, Safari H, Sari AA, Raei B, Ameri H. Assessing the performance of direct and indirect utility eliciting methods in patients with colorectal cancer: EQ-5D-5L versus C-TTO. Health Serv Outcomes Res Methodol. 2019;19(4):259-270. doi:10.1007/s10742019-00204-5
5. Ameri H, Yousefi M, Yaseri M, Nahvijou A, Arab M, Sari AA. Mapping EORTC-QLQ-C30 and QLQ-CR29 onto EQ-5D-5L in colorectal cancer patients. J Gastrointest Cancer. 2020;51(1):196-203. doi:10.1007/s12029-019-00229-6

6. Byford S, Torgerson DJ, Raftery J. Cost of illness studies. BMJ. 2000;320(7245):1335. doi:10.1136/bmj.320.7245.1335

7. Knaul FM, Arreola-Ornelas H, Méndez-Carniado O, et al. Evidence is good for your health system: policy reform to remedy catastrophic and impoverishing health spending in Mexico. Lancet. 2006;368 (9549):1828-1841. doi:10.1016/S0140-6736(06)69565-2

8. Organization WH. The World Health Report 2000: Health Systems: Improving Performance. World Health Organization; 2000.

9. Xu X, Huang X, Zhang X, Chen L, editors. Family Economic Burden of Elderly Chronic Diseases: Evidence from China. Healthcare. Multidisciplinary Digital Publishing Institute; 2019.

10. Xu X, Xu Z, Chen L, Li C. How does industrial waste gas emission affect health care expenditure in different regions of China: an application of Bayesian Quantile Regression. Int J Environ Res Public Health. 2019;16(15):2748. doi:10.3390/ijerph16152748

11. Chen L, Zhang X, Xu X. Health insurance and long-term care services for the disabled elderly in China: based on CHARLS data. Risk Manag Healthc Policy. 2020;13:155. doi:10.2147/RMHP.S233949

12. Jo C. Cost-of-illness studies: concepts, scopes, and methods. Clin Mol Hepatol. 2014;20(4):327. doi:10.3350/cmh.2014.20.4.327

13. Mohammadi Y, Baghestani E, Bahrami M, Entezarian AS, Ahmadi TG. Calculating the cost price of dialysis in Shahid Sadoughi hospital using activity based costing. Yazd. 2012;2011.

14. Ghaffari S, Mohammadzadeh A, Soliman A, Salem SP, Yousefi M. Costing in Hospital Services: Economists and Accountants'approaches. Tehran University of Medical Sciences; 2013.

15. Habetha S, Bleich S, Weidenhammer J, Fegert JM. A prevalence-based approach to societal costs occurring in consequence of child abuse and neglect. Child Adolesc Psychiatry Ment Health. 2012;6(1):35. doi:10.1186/1753-2000-6-35

16. Segel JE. Cost-of-illness studies - a primer. RTI-UNC center of excellence in health promotion economics. RTI International. 2006;1:39.

17. Taplin SH, Barlow W, Urban N, et al. Stage, age, comorbidity, and direct costs of colon, prostate, and breast cancer care. J Natl Cancer Inst. 1995;87(6):417-426. doi:10.1093/jnci/87.6.417

18. Lang H-C, Wu S-L. Lifetime costs of the top five cancers in Taiwan. Eur J Health Econ. 2012;13(3):347-353. doi:10.1007/s10198-0110307-1

19. Hajebrahimi S, Ahari AM, Ghyassi FS, Mostafaie A, Yousefi M. Holmium laser prostate enucleation (HOLEP) versus trans-urethral resection of prostate (TURP) in treatment of symptomatic prostatic enlargement; a health technology assessment. J Lasers Med Sci. 2011;2(1)

20. Organization WH. Non-Communicable Disease Prevention and Control: A Guidance Note for Investment Cases. World Health Organization; 2019.

21. Peykari N, Hashemi H, Dinarvand R, et al. National action plan for non-communicable diseases prevention and control in Iran; a response to emerging epidemic. $J$ Diabetes Metab Disord. 2017;16(1):3. doi:10.1186/s40200-017-0288-4

22. Baker D, Stachenko S, Spasoff RA, Pogson M. 47 A method for comparing and combining cost-of-illness studies: an example from cardiovascular disease. Chronic Dis Can. 2002;23(2).

23. Kim J, Lee E, Lee T, Sohn A. Economic burden of acute coronary syndrome in South Korea: a national survey. BMC Cardiovasc Disord. 2013;13(1):55. doi:10.1186/1471-2261-13-55

24. Turner H. Introduction to Generalized Linear Models. Rapport technique, Vienna University of Economics and Business; 2008.

25. Horton NJ, Laird NM. Maximum likelihood analysis of generalized linear models with missing covariates. Stat Methods Med Res. 1999;8 (1):37-50. doi:10.1177/096228029900800104 
26. Organization WH. Noncommunicable Diseases Country Profiles 2018; 2018.

27. Emamgholipour S, Sari AA, Pakdaman M, Geravandi S. Economic burden of cardiovascular disease in the Southwest of Iran. Int Cardiovasc Res J. 2018;12(1).

28. Walker IF, Garbe F, Wright J, et al. The economic costs of cardiovascular disease, diabetes mellitus, and associated complications in South Asia: a systematic review. Value Health Reg Issues. 2018;15:12-26. doi:10.1016/j.vhri.2017.05.003

29. Andrikopoulos G, Richter D, Sakellariou D, et al. High prevalence and diminished awareness of overweight and obesity in a mediterranean population. An alarming call for action. Open Cardiovasc Med J. 2012;6:141. doi:10.2174/1874192401206010141

30. Sarrafzadegan N, Mohammadifard N. Cardiovascular disease in Iran in the last 40 years: prevalence, mortality, morbidity, challenges and strategies for cardiovascular prevention. Arch Iran Med. 2019;22(4):204-210.

31. Chang H-S, Kim H-J, Nam C-M, et al. The socioeconomic burden of coronary heart disease in Korea. J Prev Med Public Health. 2012;45 (5):291. doi:10.3961/jpmph.2012.45.5.291

32. Tomas A, Tomić Z, Milijašević B, et al. Patterns of prescription antihypertensive drug utilization and adherence to treatment guidelines in the city of Novi Sad. Vojnosanit Pregl. 2016;73(6):531-537. doi:10.2298/VSP141119047T
33. Members WG, Thom $\mathrm{T}$, Haase $\mathrm{N}$, et al. Heart disease and stroke statistics-2006 update: a report from the American Heart Association Statistics Committee and Stroke Statistics Subcommittee. Circulation. 2006;113(6):e85-e151. doi:10.1161/ CIRCULATIONAHA.105.171600

34. Yang L, Wu M, Cui B, Xu J. Economic burden of cardiovascular diseases in China. Expert Rev Pharmacoecon Outcomes Res. 2008;8 (4):349-356. doi:10.1586/14737167.8.4.349

35. Ngalesoni F, Ruhago G, Norheim OF, Robberstad B. Economic cost of primary prevention of cardiovascular diseases in Tanzania. Health Policy Plan. 2015;30(7):875-884. doi:10.1093/heapol/czu088

36. Bramkamp M, Radovanovic D, Erne P, Szucs TD. Determinants of costs and the length of stay in acute coronary syndromes: a real life analysis of more than 10000 patients. Cardiovasc Drugs Ther. 2007;21(5):389-398. doi:10.1007/s10557-007-6044-0

37. Daroudi A, Zendehdel K, Nahvijou A, Zahmatkesh H, Akbarisari A. A review of methods for estimating economic burden of cancer. 2014.

38. Tabrizi JS, HaghGoshayie E, Doshmangir L, Yousefi M. New public management in Iran's health complex: a management framework for primary health care system. Prim Health Care Res Dev. 2018;19 (3):264-276. doi:10.1017/S1463423617000767
Risk Management and Healthcare Policy

\section{Publish your work in this journal}

Risk Management and Healthcare Policy is an international, peerreviewed, open access journal focusing on all aspects of public health, policy, and preventative measures to promote good health and improve morbidity and mortality in the population. The journal welcomes submitted papers covering original research, basic science, clinical \& epidemiological studies, reviews and evaluations,

\section{Dovepress}

guidelines, expert opinion and commentary, case reports and extended reports. The manuscript management system is completely online and includes a very quick and fair peer-review system, which is all easy to use. Visit http://www.dovepress.com/testimonials.php to read real quotes from published authors. 